\title{
Bounds on Iterated Coerror Functions and Their Ratios
}

\author{
By D. E. Amos
}

Abstract. Upper and lower bounds on $y_{n}=i^{n} \operatorname{erfc}(x)$ and $r_{n}=y_{n} / y_{n-1}, n \geqq 1$, $-\infty<x<\infty$, are established in terms of elementary functions. Numerical procedures for refining these bounds are presented so that $r_{n}$ and $y_{k}, k=0,1, \ldots, n$, can be computed to a specified accuracy. Some relations establishing bounds on $r_{n}^{\prime}$ and $r_{n}^{\prime \prime}$ are also derived.

Simple Bounds. Let $y_{n}(x)=i^{n} \operatorname{erfc}(x), n=-1,0,1, \cdots$. The basic inequality (see (31))

$$
P_{n}(x)=y_{n-2}(x) y_{n}(x)-y_{n-1}^{2}(x)<0, \quad n \geqq 1,
$$

expressing monotone decreasing behavior of $r_{n}(x)=y_{n}(x) / y_{n-1}(x), n \geqq 1$, in both $n$ and $x$,

$$
r_{n}^{\prime}=\frac{P_{n}(x)}{y_{n-1}^{2}(x)}=\frac{r_{n}-r_{n-1}}{r_{n-1}}<0
$$

is derived in the Appendix. The utility of this relation follows from the recurrence formulae for the iterated coerror function,

$$
\begin{gathered}
y_{-1}(x)=i^{-1} \operatorname{erfc}(x)=2 e^{-x^{2}} / \pi^{1 / 2}, \quad y_{0}(x)=i^{0} \operatorname{erfc}(x)=\operatorname{erfc}(x), \\
y_{n-2}=2 n y_{n}+2 x y_{n-1}, \quad n=1,2, \cdots
\end{gathered}
$$

to yield

$$
r_{n}^{\prime}=2 n r_{n}^{2}+2 x r_{n}-1<0, \quad n \geqq 1 .
$$

This establishes bounds on the ratios $r_{n}=y_{n} / y_{n-1}$,

$$
0<r_{n}<\frac{-x+\left(x^{2}+2 n\right)^{1 / 2}}{2 n}=B_{n}(x)
$$

since the parabola $v=2 n t^{2}+2 x t-1$ is negative between its roots. The upper bound is of most interest and we write $B_{n}(x)$ in the form

$$
\begin{aligned}
& B_{n}(x)=\frac{-x+\left(x^{2}+2 n\right)^{1 / 2}}{2 n}, \quad x<0 \\
& n \geqq 1 \text {, } \\
& =\frac{1}{x+\left(x^{2}+2 n\right)^{1 / 2}}, \quad x \geqq 0,
\end{aligned}
$$

Received October 29, 1971, revised May 23, 1972.

AMS (MOS) subject classifications (1970). Primary 65D20, 33A20; Secondary 41-04.

Key words and phrases. Iterated coerror function, error function, coerror function, Mill's ratio, probability integral. 
to avoid losses of significance in computation when $x$ is large and positive. Furthermore, if we divide (3) by $y_{n-1}$ and solve for $r_{n-1}$, we get

$$
r_{n-1}=\frac{1}{2 x+2 n r_{n}}>\frac{1}{2 x+2 n B_{n}(x)}=B_{n}(x), \quad n \geqq 1 \text {. }
$$

Thus, we have (with a shift of index)

$$
C_{n}(x)<r_{n}<D_{n}(x),
$$

and recursion on (7) in the form $C_{n} y_{n-1}<y_{n}<D_{n} y_{n-1}$ produces

$$
\operatorname{erfc}(x) \prod_{k=1}^{n} C_{k}(x)<y_{n}<\operatorname{erfc}(x) \prod_{k=1}^{n} D_{k}(x)
$$

where, in this context,

$$
C_{k}(x)=B_{k+1}(x) \text { and } D_{k}(x)=B_{k}(x) .
$$

Table 1 gives some numerical results for these bounds. Both relative and absolute errors can be assessed. The number of significant digits in $y_{n}$ is approximately the

\begin{tabular}{|c|c|c|c|c|c|}
\hline$n \backslash x$ & -10 & -5 & 0 & 5 & 10 \\
\hline 1 & $\begin{array}{l}1.005 \mathrm{E}+01 \\
1.000 \mathrm{E}+01 \\
5.050 \mathrm{E}+00\end{array}$ & $\begin{array}{l}5.098 \mathrm{E}+00 \\
5.000 \mathrm{E}+00 \\
2.596 \mathrm{E}+00\end{array}$ & $\begin{array}{l}7.071 \mathrm{E}-01 \\
5.642 \mathrm{E}-01 \\
5.000 \mathrm{E}-01\end{array}$ & $\begin{array}{l}9.808 \mathrm{E}-02 \\
9.635 \mathrm{E}-02 \\
9.629 \mathrm{E}-02\end{array}$ & $\begin{array}{l}4.975 \mathrm{E}-02 \\
4.951 \mathrm{E}-02 \\
4.951 \mathrm{E}-02\end{array}$ \\
\hline 10 & $\begin{array}{l}1.048 \mathrm{E}+00 \\
1.043 \mathrm{E}+00 \\
9.566 \mathrm{E}-01\end{array}$ & $\begin{array}{l}5.854 \mathrm{E}-01 \\
5.788 \mathrm{E}-01 \\
5.389 \mathrm{E}-01\end{array}$ & $\begin{array}{l}2.236 \mathrm{E}-01 \\
2.181 \mathrm{E}-01 \\
2.132 \mathrm{E}-01\end{array}$ & $\begin{array}{l}8.541 \mathrm{E}-02 \\
8.449 \mathrm{E}-02 \\
8.435 \mathrm{E}-02\end{array}$ & $\begin{array}{l}4.772 \mathrm{E}-02 \\
4.753 \mathrm{E}-02 \\
4.752 \mathrm{E}-02\end{array}$ \\
\hline 20 & $\begin{array}{l}5.458 \mathrm{E}-01 \\
5.438 \mathrm{E}-01 \\
5.218 \mathrm{E}-01\end{array}$ & $\begin{array}{l}3.266 \mathrm{E}-01 \\
3.240 \mathrm{E}-01 \\
3.139 \mathrm{E}-01\end{array}$ & $\begin{array}{l}1.581 \mathrm{E}-01 \\
1.562 \mathrm{E}-01 \\
1.543 \mathrm{E}-01\end{array}$ & $\begin{array}{l}7.656 \mathrm{E}-02 \\
7.598 \mathrm{E}-02 \\
7.584 \mathrm{E}-02\end{array}$ & $\begin{array}{l}4.580 \mathrm{E}-02 \\
4.564 \mathrm{E}-02 \\
4.563 \mathrm{E}-02\end{array}$ \\
\hline 50 & $\begin{array}{l}2.414 \mathrm{E}-01 \\
2.408 \mathrm{E}-01 \\
2.374 \mathrm{E}-01\end{array}$ & $\begin{array}{l}1.618 \mathrm{E}-01 \\
1.612 \mathrm{E}-01 \\
1.595 \mathrm{E}-01\end{array}$ & $\begin{array}{l}1.000 \mathrm{E}-01 \\
9.950 \mathrm{E}-02 \\
9.901 \mathrm{E}-02\end{array}$ & $\begin{array}{l}6.180 \mathrm{E}-02 \\
6.156 \mathrm{E}-02 \\
6.146 \mathrm{E}-02\end{array}$ & $\begin{array}{l}4.142 \mathrm{E}-02 \\
4.132 \mathrm{E}-\mathrm{O} 2 \\
4.130 \mathrm{E}-02\end{array}$ \\
\hline 100 & $\begin{array}{l}1.366 \mathrm{E}-01 \\
1.364 \mathrm{E}-01 \\
1.355 \mathrm{E}-01\end{array}$ & $\begin{array}{l}1.000 \mathrm{E}-01 \\
9.978 \mathrm{E}-02 \\
9.934 \mathrm{E}-02\end{array}$ & $\begin{array}{l}7.071 \mathrm{E}-02 \\
7.053 \mathrm{E}-02 \\
7.036 \mathrm{E}-02\end{array}$ & $\begin{array}{l}5.000 \mathrm{E}-02 \\
4.989 \mathrm{E}-02 \\
4.983 \mathrm{E}-02\end{array}$ & $\begin{array}{l}3.660 \mathrm{E}-02 \\
3.654 \mathrm{E}-02 \\
3.653 \mathrm{E}-02\end{array}$ \\
\hline 200 & $\begin{array}{l}8.090 \mathrm{E}-02 \\
8.082 \mathrm{E}-02 \\
8.061 \mathrm{E}-02\end{array}$ & $\begin{array}{l}6.404 \mathrm{E}-02 \\
6.396 \mathrm{E}-02 \\
6.384 \mathrm{E}-02\end{array}$ & $\begin{array}{l}5.000 \mathrm{E}-02 \\
4.994 \mathrm{E}-02 \\
4.988 \mathrm{E}-02\end{array}$ & $\begin{array}{l}3.904 \mathrm{E}-02 \\
3.899 \mathrm{E}-02 \\
3.897 \mathrm{E}-02\end{array}$ & $\begin{array}{l}3.090 \mathrm{E}-02 \\
3.08 \mathrm{TE}-02 \\
3.086 \mathrm{E}-02\end{array}$ \\
\hline
\end{tabular}
minimum number in agreement between $C_{k}$ and $D_{k}$ as $k$ ranges from 1 to $n$.

TABLE 1

$C_{n}$ and $D_{n}$ of (9) compared with $r_{n}$ 
For $x \geqq 0$, the upper bound of (7) immediately implies

$$
\begin{aligned}
& y_{n}(x)<\frac{y_{n-1}(x)}{x+\left(x^{2}+2 n\right)^{1 / 2}} \leqq \frac{y_{n-1}(x)}{(2 n)^{\frac{1}{2}}<y_{n-1}(x),} n \geqq 1, x \geqq 0 . \\
& y_{n}(x) \leqq \frac{y_{n-1}(x)}{x+\left(x^{2}+2\right)^{1 / 2}},
\end{aligned}
$$

$y_{n}<y_{n-1}$ can also be established for $n \geqq 0$ by induction on

$$
y_{n}(x)=\int_{x}^{\infty} y_{n-1}(t) d t, \quad n \geqq 0,
$$

and the upper bound in Mill's ratio [4], [14, p. 343]

$$
\begin{aligned}
m(x) & =\frac{\pi / 2}{(\pi-1) x+\left(x^{2}+\pi\right)^{1 / 2}} \leqq \frac{i^{0} \operatorname{erfc}(x)}{i^{-1} \operatorname{erfc}(x)} \\
& \leqq \frac{\pi / 2}{2 x+\left([(\pi-2) x]^{2}+\pi\right)^{1 / 2}}=M(x), \quad x \geqq 0 .
\end{aligned}
$$

(See references for other results on Mill's ratio.) With these inequalities, purely elementary bounds on $y_{n}$ can be given:

$$
\begin{gathered}
\frac{2 m(x) e^{-x^{2}}}{\pi^{1 / 2}} \leqq y_{0} \leqq \frac{2 M(x) e^{-x^{2}}}{\pi^{1 / 2}}, \quad x \geqq 0, \\
\frac{2 m(x) e^{-x^{2}}}{\pi^{1 / 2}} \prod_{k=1}^{n} C_{k}(x)<y_{n}<\frac{2 M(x) e^{-x^{2}}}{\pi^{1 / 2}} \prod_{k=1}^{n} D_{k}(x), \quad x \geqq 0, n \geqq 1 .
\end{gathered}
$$

Elementary bounds for $x<0$ follow from the identity $\operatorname{erfc}(x)=2-\operatorname{erfc}(-x)$. An upper bound on $y_{n}(x)$ for $x \geqq 0$ can be obtained from (11) and (12) by induction

$$
y_{n}(x) \leqq-\frac{2}{\pi^{1 / 2}}[M(x)]^{n+1} e^{-x^{2}}, \quad n \geqq 0, x \geqq 0,
$$

using $M(t) \leqq M(x)$ for $t \geqq x$. Simple backward recursion in (10), followed by (12), gives complementary forms

$$
\begin{aligned}
& y_{n}(x) \leqq \frac{2 / \pi^{1 / 2} M(x) e^{-x^{2}}}{2^{n / 2}(n !)^{1 / 2}}, \\
& y_{n}(x) \leqq \frac{2 / \pi^{1 / 2} M(x) e^{-x^{2}}}{\left(x+\left(x^{2}+2\right)^{1 / 2}\right)^{n}},
\end{aligned}
$$

While the bounds in (7) were obtained from $r_{n}^{\prime}<0$ and are best for large positive $x$, Eq. (36), $r_{n}^{\prime}>-1 / n$, represents the other extreme, and bounds from this inequality would be best for large negative $x$. They are (7) with

$$
\begin{array}{cc}
C_{n}(x)=\frac{-x+\left(x^{2}+2 n-2\right)^{1 / 2}}{2 n}, & x<0, \\
=\frac{1-1 / n}{x+\left(x^{2}+2 n-2\right)^{1 / 2}}, & x \geqq 0, \\
D_{n}(x)=B_{n}(x) . &
\end{array}
$$

Table 2 shows the results for these bounds. 
TABLE 2

$C_{n}$ and $D_{n}$ of (16) compared with $r_{n}$

\begin{tabular}{|c|c|c|c|c|c|}
\hline$n \backslash x$ & -10 & -5 & 0 & 5 & 10 \\
\hline 1 & $\begin{array}{l}1.005 \mathrm{E}+01 \\
1.000 \mathrm{E}+01 \\
1.000 \mathrm{E}+01\end{array}$ & $\begin{array}{l}5.098 \mathrm{E}+00 \\
5.000 \mathrm{E}+00 \\
5.000 \mathrm{E}+00\end{array}$ & $\begin{array}{l}7.071 \mathrm{E}-01 \\
5.642 \mathrm{E}-01 \\
0 .\end{array}$ & $\begin{array}{l}9.808 \mathrm{E}-02 \\
9.635 \mathrm{E}-02 \\
0 .\end{array}$ & $\begin{array}{l}4.975 \mathrm{E}-02 \\
4.951 \mathrm{E}-02 \\
0 .\end{array}$ \\
\hline 10 & $\begin{array}{l}1.048 E+00 \\
1.043 E+00 \\
1.043 E+00\end{array}$ & $\begin{array}{l}5.854 \mathrm{E}-01 \\
5.788 \mathrm{E}-01 \\
5.779 \mathrm{E}-01\end{array}$ & $\begin{array}{l}2.236 \mathrm{E}-01 \\
2.181 \mathrm{E}-01 \\
2.121 \mathrm{E}-01\end{array}$ & $\begin{array}{l}8.541 \mathrm{E}-02 \\
8.449 \mathrm{E}-02 \\
7.78 \mathrm{TE}-02\end{array}$ & $\begin{array}{l}4.772 \mathrm{E}-02 \\
4.753 \mathrm{E}-02 \\
4.314 \mathrm{E}-02\end{array}$ \\
\hline 20 & $\begin{array}{l}5.458 \mathrm{E}-01 \\
5.438 \mathrm{E}-01 \\
5.437 \mathrm{E}-01\end{array}$ & $\begin{array}{l}3.266 \mathrm{E}-01 \\
3.240 \mathrm{E}-01 \\
3.234 \mathrm{E}-01\end{array}$ & $\begin{array}{l}1.581 \mathrm{E}-01 \\
1.562 \mathrm{E}-01 \\
1.541 \mathrm{E}-01\end{array}$ & $\begin{array}{l}7.656 \mathrm{E}-02 \\
7.598 \mathrm{E}-02 \\
7.343 \mathrm{E}-02\end{array}$ & $\begin{array}{l}4.580 \mathrm{E}-02 \\
4.564 \mathrm{E}-02 \\
4.368 \mathrm{E}-02\end{array}$ \\
\hline 50 & $\begin{array}{l}2.414 \mathrm{E}-01 \\
2.408 \mathrm{E}-01 \\
2.407 \mathrm{E}-01\end{array}$ & $\begin{array}{l}1.618 \mathrm{E}-01 \\
1.612 \mathrm{E}-01 \\
1.609 \mathrm{E}-01\end{array}$ & $\begin{array}{l}1.000 \mathrm{E}-01 \\
9.950 \mathrm{E}-02 \\
9.899 \mathrm{E}-02\end{array}$ & $\begin{array}{l}6.180 \mathrm{E}-02 \\
6.156 \mathrm{E}-02 \\
6.091 \mathrm{E}-02\end{array}$ & $\begin{array}{l}4.142 \mathrm{E}-02 \\
4.132 \mathrm{E}-02 \\
4.071 \mathrm{E}-02\end{array}$ \\
\hline 100 & $\begin{array}{l}1.366 \mathrm{E}-01 \\
1.364 \mathrm{E}-01 \\
1.363 \mathrm{E}-01\end{array}$ & $\begin{array}{l}1.000 \mathrm{E}-01 \\
9.978 \mathrm{E}-02 \\
9.967 \mathrm{E}-02\end{array}$ & $\begin{array}{l}7.071 \mathrm{E}-02 \\
7.053 \mathrm{E}-02 \\
7.036 \mathrm{E}-02\end{array}$ & $\begin{array}{l}5.000 \mathrm{E}-02 \\
4.989 \mathrm{E}-02 \\
4.96 \mathrm{TE}-02\end{array}$ & $\begin{array}{l}3.660 \mathrm{E}-\infty 2 \\
3.654 \mathrm{E}-02 \\
3.63 \mathrm{~J}-02\end{array}$ \\
\hline 200 & $\begin{array}{l}8.090 \mathrm{E}-02 \\
8.082 \mathrm{E}-02 \\
8.079 \mathrm{E}-02\end{array}$ & $\begin{array}{l}6.404 \mathrm{E}-02 \\
6.396 \mathrm{E}-02 \\
6.392 \mathrm{E}-02\end{array}$ & $\begin{array}{l}5.000 \mathrm{E}-02 \\
4.994 \mathrm{E}-02 \\
4.987 \mathrm{E}-02\end{array}$ & $\begin{array}{l}3.904 \mathrm{E}-02 \\
3.899 \mathrm{E}-02 \\
3.892 \mathrm{E}-02\end{array}$ & $\begin{array}{l}3.090 \mathrm{E}-02 \\
3.087 \mathrm{E}-02 \\
3.079 \mathrm{E}-02\end{array}$ \\
\hline
\end{tabular}

Bounds on $y_{n} / y_{n-k}$ can be obtained by bounding each term of

$$
y_{n} / y_{n-k}=r_{n} r_{n-1} \cdots r_{n-k+1} \text {. }
$$

Improved Bounds. The simplicity of the previous bounds is appealing; however, they are not very sharp near $x=0$. The results of this section improve this situation. Relation (35) in the Appendix is

$$
\begin{array}{rlrl}
r_{n}^{\prime}=2 n r_{n}^{2}+2 x r_{n}-1 & <-r_{n}^{2}, & x \geqq 0, \quad n \geqq 1 . \\
& <-r_{n}^{2} \exp \left\{-x^{2}\right\}, & x<0, &
\end{array}
$$

Following through as before, we get (7) with the bounds

$$
\begin{array}{rlrl}
C_{n}(x) & =\frac{2 n+2+\exp \left\{-x^{2}\right\}}{2 x \exp \left\{-x^{2}\right\}+(2 n+2) / D_{n+1}(x)}>D_{n+1}(x), & & x<0, \\
& =\frac{2 n+3}{(2 n+4) x+(2 n+2)\left(x^{2}+2 n+3\right)^{1 / 2},} \quad x \geqq 0, \\
D_{n}(x) & =\frac{-x+\left(x^{2}+2 n+\exp \left\{-x^{2}\right\}\right)^{1 / 2}}{2 n+\exp \left\{-x^{2}\right\}}, \quad x<0, & \\
& =\frac{1}{x+\left(x^{2}+2 n+1\right)^{1 / \overline{2}}}, \quad x \geqq 0, &
\end{array}
$$


TABLE 3

$C_{n}$ and $D_{n}$ of (17) compared with $r_{n}$

\begin{tabular}{|c|c|c|c|c|c|}
\hline$n \backslash x$ & -10 & -5 & 0 & 5 & 10 \\
\hline 1 & $\begin{array}{l}1.005 \mathrm{E}+01 \\
1.000 \mathrm{E}+01 \\
5.050 \mathrm{E}+00\end{array}$ & $\begin{array}{l}5.098 \mathrm{E}+00 \\
5.000 \mathrm{E}+00 \\
2.596 \mathrm{E}+00\end{array}$ & $\begin{array}{l}5.774 \mathrm{E}-01 \\
5.642 \mathrm{E}-01 \\
5.590 \mathrm{E}-01\end{array}$ & $\begin{array}{l}9.71 \mathrm{E}-02 \\
9.635 \mathrm{E}-02 \\
9.632 \mathrm{E}-02\end{array}$ & $\begin{array}{l}4.963 \mathrm{E}-02 \\
4.951 \mathrm{E}-02 \\
4.951 \mathrm{E}-02\end{array}$ \\
\hline 10 & $\begin{array}{l}1.048 \mathrm{E}+00 \\
1.043 \mathrm{E}+00 \\
9.566 \mathrm{E}-01\end{array}$ & $\begin{array}{l}5.854 \mathrm{E}-01 \\
5.788 \mathrm{E}-01 \\
5.389 \mathrm{E}-01\end{array}$ & $\begin{array}{l}2.182 \mathrm{E}-01 \\
2.181 \mathrm{E}-01 \\
2.180 \mathrm{E}-01\end{array}$ & $\begin{array}{l}8.487 \mathrm{E}-02 \\
8.449 \mathrm{E}-02 \\
8.443 \mathrm{E}-02\end{array}$ & $\begin{array}{l}4.762 \mathrm{E}-02 \\
4.753 \mathrm{E}-02 \\
4.752 \mathrm{E}-02 .\end{array}$ \\
\hline 20 & $\begin{array}{l}5.458 \mathrm{E}-01 \\
5.438 \mathrm{E}-01 \\
5.218 \mathrm{E}-01\end{array}$ & $\begin{array}{l}3.266 \mathrm{E}-01 \\
3.240 \mathrm{E}-01 \\
3.139 \mathrm{E}-01\end{array}$ & $\begin{array}{l}1.562 \mathrm{E}-01 \\
1.562 \mathrm{E}-01 \\
1.561 \mathrm{E}-01\end{array}$ & $\begin{array}{l}7.620 \mathrm{E}-02 \\
7.598 \mathrm{E}-02 \\
7.593 \mathrm{E}-02\end{array}$ & $\begin{array}{l}4.572 \mathrm{E}-02 \\
4.564 \mathrm{E}-02 \\
4.564 \mathrm{E}-02\end{array}$ \\
\hline 50 & $\begin{array}{l}2.414 \mathrm{E}-01 \\
2.408 \mathrm{E}-01 \\
2.374 \mathrm{E}-01\end{array}$ & $\begin{array}{l}1.618 \mathrm{E}-01 \\
1.612 \mathrm{E}-01 \\
1.595 \mathrm{E}-01\end{array}$ & $\begin{array}{l}9.950 \mathrm{E}-02 \\
9.950 \mathrm{E}-02 \\
9.950 \mathrm{E}-02\end{array}$ & $\begin{array}{l}6.163 \mathrm{E}-02 \\
6.156 \mathrm{E}-02 \\
6.153 \mathrm{E}-02\end{array}$ & $\begin{array}{l}4.136 \mathrm{E}-02 \\
4.132 \mathrm{E}-02 \\
4.13 \mathrm{IE}-02\end{array}$ \\
\hline 100 & $\begin{array}{l}1.366 \mathrm{E}-01 \\
1.364 \mathrm{E}-01 \\
1.355 \mathrm{E}-01\end{array}$ & $\begin{array}{l}1.000 \mathrm{E}-01 \\
9.978 \mathrm{E}-02 \\
9.934 \mathrm{E}-02\end{array}$ & $\begin{array}{l}7.053 \mathrm{E}-02 \\
7.053 \mathrm{E}-02 \\
7.053 \mathrm{E}-02\end{array}$ & $\begin{array}{l}4.992 \mathrm{E}-02 \\
4.989 \mathrm{E}-02 \\
4.988 \mathrm{E}-02\end{array}$ & $\begin{array}{l}3.656 \mathrm{E}-02 \\
3.654 \mathrm{E}-02 \\
3.654 \mathrm{E}-02\end{array}$ \\
\hline 200 & $\begin{array}{l}8.090 \mathrm{E}-02 \\
8.082 \mathrm{E}-02 \\
8.061 \mathrm{E}-02\end{array}$ & $\begin{array}{l}6.404 \mathrm{E}-02 \\
6.396 \mathrm{E}-02 \\
6.384 \mathrm{E}-02\end{array}$ & $\begin{array}{l}4.994 \mathrm{E}-02 \\
4.994 \mathrm{E}-02 \\
4.994 \mathrm{E}-02\end{array}$ & $\begin{array}{l}3.900 \mathrm{E}-02 \\
3.899 \mathrm{E}-02 \\
3.899 \mathrm{E}-02\end{array}$ & $\begin{array}{l}3.088 \mathrm{E}-02 \\
3.08 \mathrm{TE}-02 \\
3.08 \mathrm{TE}-02\end{array}$ \\
\hline
\end{tabular}

whose derivatives of order 2 or greater are discontinuous at $x=0$. (The other half of (35) leads to $C_{n}(x)$ in (9).) Table 3 shows these results for some numerical values. Notice also that for $x<0, D_{n+1}$ is a lower bound on $r_{n}$. While these bounds are relatively good at $x=0$, they can be made sharp by observing that

$$
r_{n}^{\prime}=2 n r_{n}^{2}+2 x r_{n}-1 \gtrless r_{n}^{\prime}(0)=2 n r_{n}^{2}(0)-1, \quad x \gtrless 0
$$

is exact at $x=0$, where

$$
r_{n}(0)=\frac{\Gamma((n+1) / 2)}{2 \Gamma(n / 2+1)}, \quad n \geqq 0 .
$$

The inequalities in (18) follow from (38) which shows that $r_{n}^{\prime}$ is monotone increasing in $x$. The roots give

$$
\begin{array}{ll}
D_{n}(x)=\frac{-x+\left(x^{2}+2 n a_{n}\right)^{1 / 2}}{2 n}, & x<0, \\
C_{n}(x)=\frac{a_{n}}{x+\left(x^{2}+2 n a_{n}\right)^{1 / 2}}, & x \geqq 0,
\end{array}
$$

where $a_{n}=2 n r_{n}^{2}(0)$ and, with (6), 
(20b)

$$
\begin{array}{ll}
C_{n}(x)=\frac{-x+\left(x^{2}+2(n+1) a_{n+1}\right)^{1 / 2}}{2(n+1) a_{n+1}}, & x<0, \\
D_{n}(x)=\frac{1}{x+\left(x^{2}+2(n+1) a_{n+1}\right)^{1 / 2}}, & x \geqq 0 .
\end{array}
$$

Table 4 shows the partial improvement over Tables 1, 2 and 3. Bounds analogous to those in (10) and (15) can be formed for $x \geqq 0$ by setting $x=0$ or $n=1$ in $D_{n}(x)$ of (20b). The largest lower bound and the smallest upper bound among the formulae listed would be the best over the range of interest in $n$ and $x$.

Iterative improvements, generating upper and lower bounds at each step, can be made by recurring backward on (6), starting the continued fraction approximants with some $C_{n}$ and $D_{n}$ (see also the next section on numerical computations).

The connection between these bounds and Mill's ratio can be established by taking (6) with $n=1$ and applying the expressions for $C_{1}(x)$ or $D_{1}(x)$. (20a) for $x \geqq 0$ gives the upper bound quoted in the NBS handbook [1, p. 298] while (5) for $x \geqq 0$ gives the lower bound in the same reference. (20b) gives Boyd's [4] lower bound (12).

The bounds in (12) are fairly sharp with maximum relative errors of $1.17 \%$ and $0.91 \%$, respectively. Best results are obtained with $M(x)$ for $x \leqq 0.85$ and $m(x)$ for $x>0.85$, with an overall maximum relative error for this combination of about $0.86 \%$.

TABLE 4

\begin{tabular}{|c|c|c|c|c|c|}
\hline$n \backslash x$ & -10 & -5 & 0 & 5 & 10 \\
\hline 1 & $\begin{array}{l}1.003 \mathrm{E}+01 \\
1.000 \mathrm{E}+01 \\
6.416 \mathrm{E}+00\end{array}$ & $\begin{array}{l}5.063 E+00 \\
5.000 E+00 \\
3.280 E+00\end{array}$ & $\begin{array}{l}5.642 \mathrm{E}-01 \\
5.642 \mathrm{E}-01 \\
5.642 \mathrm{E}-01\end{array}$ & $\begin{array}{l}9.704 \mathrm{E}-02 \\
9.635 \mathrm{E}-02 \\
6.287 \mathrm{E}-02\end{array}$ & $\begin{array}{l}4.961 \mathrm{E}-02 \\
4.951 \mathrm{E}-02 \\
3.173 \mathrm{E}-02\end{array}$ \\
\hline 10 & $\begin{array}{l}1.045 \mathrm{E}+00 \\
1.043 \mathrm{E}+00 \\
9.989 \mathrm{E}-01\end{array}$ & $\begin{array}{l}5.818 \mathrm{E}-01 \\
5.788 \mathrm{E}-01 \\
5.605 \mathrm{E}-01\end{array}$ & $\begin{array}{l}2.181 \mathrm{E}-01 \\
2.181 \mathrm{E}-01 \\
2.181 \mathrm{E}-01\end{array}$ & $\begin{array}{l}8.486 \mathrm{E}-02 \\
8.449 \mathrm{E}-02 \\
8.176 \mathrm{E}-02\end{array}$ & $\begin{array}{l}4.762 \mathrm{E}-02 \\
4.753 \mathrm{E}-02 \\
4.550 \mathrm{E}-02\end{array}$ \\
\hline 20 & $\begin{array}{l}5.448 \mathrm{E}-01 \\
5.438 \mathrm{E}-01 \\
5.334 \mathrm{E}-01\end{array}$ & $\begin{array}{l}3.250 \mathrm{E}-01 \\
3.240 \mathrm{E}-01 \\
3.200 \mathrm{E}-01\end{array}$ & $\begin{array}{l}1.562 \mathrm{E}-01 \\
1.562 \mathrm{E}-01 \\
1.562 \mathrm{E}-01\end{array}$ & $\begin{array}{l}7.619 \mathrm{E}-02 \\
7.598 \mathrm{E}-02 \\
7.502 \mathrm{E}-02\end{array}$ & $\begin{array}{l}4.571 \mathrm{E}-02 \\
4.564 \mathrm{E}-02 \\
4.476 \mathrm{E}-02\end{array}$ \\
\hline 50 & $\begin{array}{l}2.411 \mathrm{E}-01 \\
2.408 \mathrm{E}-01 \\
2.394 \mathrm{E}-01\end{array}$ & $\begin{array}{l}1.614 \mathrm{E}-01 \\
1.612 \mathrm{E}-01 \\
1.606 \mathrm{E}-01\end{array}$ & $\begin{array}{l}9.950 \mathrm{E}-02 \\
9.950 \mathrm{E}-02 \\
9.950 \mathrm{E}-02\end{array}$ & $\begin{array}{l}6.163 \mathrm{E}-02 \\
6.156 \mathrm{E}-02 \\
6.136 \mathrm{E}-02\end{array}$ & $\begin{array}{l}4.136 \mathrm{E}-02 \\
4.132 \mathrm{E}-02 \\
4.107 \mathrm{E}-02\end{array}$ \\
\hline 100 & $\begin{array}{l}1.365 \mathrm{E}-01 \\
1.364 \mathrm{E}-01 \\
1.361 \mathrm{E}-01\end{array}$ & $\begin{array}{l}9.983 \mathrm{E}-02 \\
9.978 \mathrm{E}-02 \\
9.967 \mathrm{E}-02\end{array}$ & $\begin{array}{l}7.053 \mathrm{E}-02 \\
7.053 \mathrm{E}-02 \\
7.053 \mathrm{E}-02\end{array}$ & $\begin{array}{l}4.992 \mathrm{E}-02 \\
4.989 \mathrm{E}-02 \\
4.983 \mathrm{E}-02\end{array}$ & $\begin{array}{l}3.656 \mathrm{E}-02 \\
3.654 \mathrm{E}-02 \\
3.646 \mathrm{E}-02\end{array}$ \\
\hline 200 & $\begin{array}{l}8.085 \mathrm{E}-02 \\
8.082 \mathrm{E}-02 \\
8.076 \mathrm{E}-02\end{array}$ & $\begin{array}{l}6.398 \mathrm{E}-02 \\
6.396 \mathrm{E}-02 \\
6.394 \mathrm{E}-02\end{array}$ & $\begin{array}{l}4.994 \mathrm{E}-02 \\
4.994 \mathrm{E}-02 \\
4.994 \mathrm{E}-02\end{array}$ & $\begin{array}{l}3.900 \mathrm{E}-02 \\
3.899 \mathrm{E}-02 \\
3.898 \mathrm{E}-02\end{array}$ & $\begin{array}{l}3.088 \mathrm{E}-02 \\
3.08 \mathrm{FE}-02 \\
3.085 \mathrm{E}-02\end{array}$ \\
\hline
\end{tabular}

$C_{n}$ and $D_{n}$ of (20) compared with $r_{n}$ 
Numerical Computation of $r_{n}$ and $y_{k}, k=0,1, \cdots, n$. In [5] and [6], Gautschi shows that forward recursion on (3) is appropriate for $x \leqq 0$ while an iterative backward technique on (6) (which generates continued fraction approximants) is appropriate for $x>0$ for stability. It would be hard to improve on the simplicity of the forward recursion for $x \leqq 0$ but some improvement is possible for $x>0$ because the continued fraction approximants are slowly convergent for $x$ close to zero. The results developed above are exploited to get accurate values of $r_{n}$ so that the ratios

$$
r_{k-1}=\frac{.5}{x+k r_{k}}, \quad k=n, n-1, \cdots, 1, \quad x>0,
$$

can be computed for the relation

$$
y_{k}=\frac{2 e^{-x^{2}}}{\pi^{1 / 2}} \prod_{i=0}^{k} r_{i}, \quad k=0,1,2, \cdots, n, \quad x>0 .
$$

The method which has proved successful in computing $r_{n}$ is based upon a restatement of (21) with $k$ replaced by $k+1$,

$$
\left[2(k+1)\left(r_{k+1} / r_{k}\right) r_{k}+2 x\right] r_{k}=1,
$$

in the form

$$
r_{k}=\frac{1}{x+\left(x^{2}+2(k+1) R_{k+1}\right)^{1 / 2}}, \quad R_{k+1}=\frac{r_{k+1}}{r_{k}} .
$$

Then, with $D_{k}$ of (20b) as an initial approximation to $r_{k}$ for $k \geqq n$ (see Table 4), the algorithm becomes

$$
r_{k}^{0}=\frac{1}{x+\left(x^{2}+\left[2(k+1) r_{k+1}(0)\right]^{2}\right)^{1 / \overline{2}}}, \quad k=n, n+1, \cdots, n+\nu, x \geqq 0,
$$

where $r_{k}(0)$ is defined in (19), and

$$
\begin{aligned}
& R_{k+1}^{m}=r_{k+1}^{m} / r_{k}^{m}, \quad k=n, n+1, \cdots, n+\nu-m-1, \\
& r_{k}^{m+1}=\frac{1}{x+\left(x^{2}+2(k+1) R_{k+1}^{m}\right)^{1 / 2}}, \quad m=0,1,2, \cdots, \nu-1 .
\end{aligned}
$$

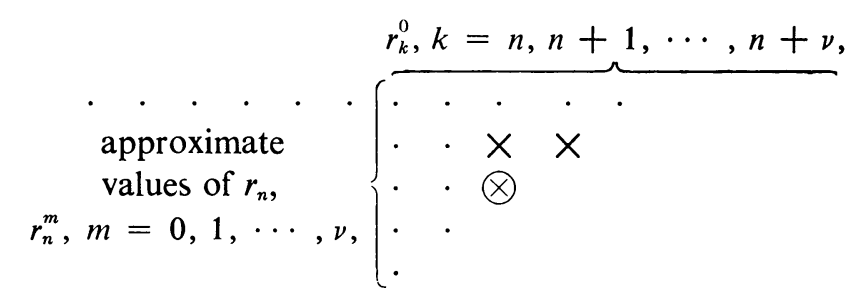

FIGURE 1

The iteration diagram is shown in Fig. 1. $r_{n}^{\nu}$ is the approximate value of $r_{n}$, and only two successive diagonals need be stored.

Although the convergence proof below does not show that $r_{k}^{m}$ decreases monotonically to $r_{k}$ on the columns of Fig. 1, the numerical results were all of this character. If this were true in general, it would follow, on using (21), that 


$$
c_{n}^{\nu}=\frac{1}{2 x+2(n+1) r_{n+1}^{\nu-1}} \leqq r_{n} \leqq r_{n}^{\nu},
$$

and the error criterion

$$
\left|r_{n}^{\nu}-r_{n}\right| / r_{n} \leqq\left|r_{n}^{\nu}-c_{n}^{\nu}\right| / c_{n}^{\nu} \leqq \epsilon
$$

could be used to terminate the process to guarantee a relative error $\epsilon$. Even if the monotonicity is violated, this is a sensible method of termination since $r_{n+1}^{\nu-1}$, and hence $c_{n}^{\nu}$, can be expected to be slightly less accurate than $r_{n}^{\nu}$. The construction of rigorous bounds using (23a) is shown in the convergence proof of the algorithm.

Some experimentation shows that if $n<25$ (say) and $x<2, n$ should be increased to 25 before the iteration is started to increase the rate of convergence. Upon completion, the backward recursive step in (21) is applied followed by (22). Notice that for $x=0, r_{k}^{1}=r_{k}(0)$ and $\nu=1$. With a relative error $\epsilon=5 \times 10^{-9}$, extensive evaluation of this procedure showed that $\nu \leqq 5$ (a maximum of 6 applications of (23b) and 15 of (23c)) held for $x \geqq 0$ and $0 \leqq n \leqq 100$. For $n \geqq 50$ the maximum value of $\nu$ was 4 , but the number of steps in (21) to reduce the index when the starting index is small diminishes this advantage somewhat.

Straight backward recursion with (21) starting with $C_{200}$ or $D_{200}$ of (9) gave only 4 significant digits in erfc(0.1). The corresponding computation with $C_{200}$ or $D_{200}$ of (20a) or (20b), which are accurate at $x=0$, gave 6 significant figures. This amounts to iteration of these bounds according to (6) or (21). It is common to avoid underflow problems by scaling $y_{k}$ by $e^{x^{2}}$ in (22).

The forward recursive loop for $x<0$ is started with $y_{-1}(x)$ and $y_{0}(x)$ where $y_{0}(x)=2-\operatorname{erfc}(|x|)$ for $x<0$. The scheme for $x \geqq 0$ is used to compute $\operatorname{erfc}(|x|)$. If $x<X_{0}\left(X_{0}=-6\right.$ for a CDC 6600 computer), $y_{0}(x)=2$ to the word length of the machine and the erfc $(|x|)$ computation can be avoided.

The methods exploited here have concentrated on recursion, primarily for sake of computation. However, the differential inequalities developed in the Appendix can be integrated for other types of apprxoimations.

\section{Convergence of the Algorithm.}

THEOREM. If $x \geqq 0$, the sequence $r_{k}^{m}$ generated by (23c) converges to $r_{k}$ as $m \rightarrow \infty$ for each $k \geqq n \geqq 0$.

The proof consists of constructing monotone sequences of upper and lower bounds on $r_{k}^{m}$ which converge to $r_{k}$. Let $D_{k}^{0}=r_{k}^{0}$. Using (20b) and (21), we have

$$
C_{k}^{0}=\frac{1}{2 x+2(k+1) D_{k+1}^{0}} \leqq r_{k} \leqq r_{k}^{0}=D_{k}^{0}
$$

Substitution of these bounds into the expressions $r_{k+1} / r_{k}$ and $r_{k+1}^{0} / r_{k}^{0}$ yield

$$
\frac{C_{k+1}^{0}}{D_{k}^{0}} \leqq \frac{r_{k+1}}{r_{k}} \leqq \frac{D_{k+1}^{0}}{C_{k}^{0}} \text { and } \frac{C_{k+1}^{0}}{D_{k}^{0}} \leqq \frac{r_{k+1}^{0}}{r_{k}^{0}} \leqq \frac{D_{k+1}^{0}}{C_{k}^{0}} \text {. }
$$

Another substitution of the bounds in (25) into the denominators of (23a) and (23c) for $m=0$ give new bounds $D_{k}^{1}$ and $C_{k}^{1}$,

$$
D_{k}^{1} \geqq r_{k} \geqq C_{k}^{1}, \quad D_{k}^{1} \geqq r_{k}^{1} \geqq C_{k}^{1}
$$

where 
(26)

$$
D_{k}^{1}=\frac{1}{x+\left(x^{2}+2(k+1) C_{k+1}^{0} / D_{k}^{0}\right)^{1 / 2}} \quad \text { and } \quad C_{k}^{1}=\frac{1}{x+\left(x^{2}+2(k+1) D_{k+1}^{0} / C_{k}^{0}\right)^{1 / 2}} \text {. }
$$

Notice that equality holds throughout for $x=0$. Continuing in this way, we can inductively construct sequences of bounds $D_{k}^{m}$ and $C_{k}^{m}$ on $r_{k}$ and $r_{k}^{m}$. However, convergence is obtained by showing monotonicity of each sequence,

$$
D_{k}^{m+1} \leqq D_{k}^{m} \quad \text { and } \quad C_{k}^{m+1} \geqq C_{k}^{m}, \quad m=0,1,2, \cdots .
$$

Thus, for $m=0$, we need to establish $D_{k}^{0} \geqq D_{k}^{1}$ and $C_{k}^{1} \geqq C_{k}^{0}$ before going on to the induction. $D_{k}^{0} \geqq D_{k}^{1}$ follows by showing that

$$
g(x)=\frac{C_{k+1}^{0}}{D_{k}^{0}}=\frac{R_{k+3}(0)\left(x+\left(x^{2}+2(k+1) R_{k+1}(0)\right)^{1 / 2}\right)}{\left[2 R_{k+3}(0)-\frac{k+2}{k+3}\right] x+\frac{k+2}{k+3}\left(x^{2}+2(k+3) R_{k+3}(0)\right)^{1 / 2}}
$$

in the denominator of $D_{k}^{1}$ is greater than

$$
R_{k+1}(0)=r_{k+1}(0) / r_{k}(0)=2(k+1) r_{k+1}^{2}(0)
$$

in the denominator of $D_{k}^{0}$ for $x>0$. (The last expression in (27) is obtained from (6) with $x=0$ and $C_{k+1}^{0}$ is obtained from (24) by rationalizing the denominator of $D_{k+2}^{0}$.) This inequality, $g(x) \geqq R_{k+1}(0)$, can be proved by showing monotone increasing behavior of $g(x)$ together with $g(0)=R_{k+1}(0) . g(0)=R_{k+1}(0)$ follows from (25) and (27) and the fact that equality holds for $x=0$ in (25). The positivity of $g^{\prime}(x)$,

$$
\begin{aligned}
g^{\prime}(x)= & \frac{R_{k+3}(0)}{\left(x^{2}+a\right)^{1 / 2}\left(x^{2}+c\right)^{1 / 2}} \\
& \cdot\left[\frac{(a b-c d)(a b+c d) x^{2}+a c\left(a b^{2}-c d^{2}\right)+b x(a-c) A(x)}{A(x)\left(d x+b\left(x^{2}+a\right)^{1 / 2}\right)^{2}}\right],
\end{aligned}
$$

where

$$
\begin{gathered}
a=2(k+3) R_{k+3}(0), \quad c=2(k+1) R_{k+1}(0), \\
b=(k+2) /(k+3), \quad d=2 R_{k+3}(0)-b, \\
A(x)=a b\left(x^{2}+c\right)^{1 / 2}+c d\left(x^{2}+a\right)^{1 / 2},
\end{gathered}
$$

will follow if the quantities $a-c, d, a b-c d, a b^{2}-c d^{2}$ are shown to be positive.

A direct application of (33) and (39) for $x=0$ gives $a>c$ since

$$
R_{k}(x)=1+r_{k}^{\prime}(x), \quad r_{k+1}^{\prime}(x)>r_{k}^{\prime}(x) \Rightarrow R_{k+1}(x)>R_{k}(x) .
$$

On the other hand, $d>0$ follows from (33), (35) and (7), with (9), for $x=0$ since

$$
R_{k+3}(0)=1+r_{k+3}^{\prime}(0) \geqq 1-2 r_{k+3}^{2}(0)>1-\frac{2}{2(k+3)}=\frac{k+2}{k+3}=b
$$

implies $d>b>0$.

In order to deduce the signs of $a b-c d$ and $a b^{2}-c d^{2}$, we first express $R_{k+3}(0)$ in terms of $r_{k+1}(0)$ by means of (27) and (6),

$$
R_{k+3}(0)=2(k+3) r_{k+3}^{2}(0), \quad r_{k+3}(0)=\frac{k+2}{k+3} r_{k+1}(0) .
$$


Then, with (27) and (28),

$$
\begin{aligned}
a b-c d= & 4 b r_{k+1}^{2}(0)\left[(k+2)^{2}+(k+1)^{2}-4(k+1)^{2}(k+2) r_{k+1}^{2}(0)\right], \\
a b^{2}-c d^{2}= & 4 b^{2} r_{k+1}^{2}(0)\left[(2 k+3)-4(k+1)(k+2) r_{k+1}^{2}(0)\right] \\
& \cdot\left[1+4(k+1)(k+2) r_{k+1}^{2}(0)\right] .
\end{aligned}
$$

If we use (19) for $r_{k+1}(0)$ together with $\Gamma(z+1)=z \Gamma(z)$ in the denominator, we get

$$
r_{k+1}^{2}(0)=\frac{1}{(k+1)^{2}} \frac{\Gamma^{2}(k / 2+1)}{\Gamma^{2}((k+1) / 2)},
$$

and the upper bound of [18],

$$
n^{1-s} \leqq \frac{\Gamma(n+1)}{\Gamma(n+s)} \leqq(n+s)^{1-s}, \quad n>0,0 \leqq s \leqq 1,
$$

with $n=k / 2, s=1 / 2$, suffices to establish the sign of $a b-c d$,

$$
a b-c d \geqq 4 b r_{k+1}^{2}(0)\left[2 k^{2}+6 k+5-4(k+2)\left(\frac{k+1}{2}\right)\right]=4 b r_{k+1}^{2}(0)>0 .
$$

However, sharper results are needed to show $a b^{2}-c d^{2}>0$ for $k \geqq 0$. The results stated in (45) can be applied, for $k \geqq 4$,

$$
\frac{\Gamma^{2}(k / 2+1)}{\Gamma^{2}((k+1) / 2)}<\frac{k}{2}+\frac{1}{4}+\frac{1}{16 k}-\frac{1}{32 k^{2}}+\frac{48}{5 k^{3}}, \quad k \geqq 4,
$$

and this yields

$$
a b^{2}-c d^{2}>\frac{4 b^{2} r_{k+1}^{2}(0)}{k+1}\left[\frac{3}{4}-\frac{3}{8 k}-\frac{763}{20 k^{2}}-\frac{384}{5 k^{3}}\right]\left[1+4(k+1)(k+2) r_{k+1}^{2}(0)\right]>0
$$

for $k \geqq 9$. Direct substitution was used to verify $a b^{2}-c d^{2}>0$ for $k=0$ through $k=9$. Thus, $D_{k}^{0} \geqq D_{k}^{1}$ with strict inequality for $x>0$.

For $C_{k}^{1}$, we take the defining equation (26) and substitute (24) for $C_{k}^{0}$ to get

$$
C_{k}^{1}=\frac{1}{x+\left(x^{2}+2(k+1) D_{k+1}^{0}\left(2 x+2(k+1) D_{k+1}^{0}\right)\right)^{1 / 2}}=\frac{1}{2 x+2(k+1) D_{k+1}^{0}}=C_{k}^{0} .
$$

To summarize the situation for $m=0$, we have

$$
D_{k}^{0} \geqq D_{k}^{1} \geqq r_{k} \geqq C_{k}^{1}=C_{k}^{0} \quad \text { and } \quad D_{k}^{0} \geqq D_{k}^{1} \geqq r_{k}^{1} \geqq C_{k}^{1}=C_{k}^{0} .
$$

Now, we repeat the induction steps (24) through (26) for $m=1$. Thus, (29) applied to $r_{k+1} / r_{k}$ and $r_{k+1}^{1} / r_{k}^{1}$ yields

$$
\frac{C_{k+1}^{1}}{D_{k}^{1}} \leqq \frac{r_{k+1}}{r_{k}} \leqq \frac{D_{k+1}^{1}}{C_{k}^{1}} \text { and } \frac{C_{k+1}^{1}}{D_{k}^{1}} \leqq \frac{r_{k+1}^{1}}{r_{k}^{1}} \leqq \frac{D_{k+1}^{1}}{C_{k}^{1}}
$$

These expressions with (23a) and (23c) for $m=1$ give new bounds $D_{k}^{2}$ and $C_{k}^{2}$,

$$
D_{k}^{2} \geqq r_{k} \geqq C_{k}^{2}, \quad D_{k}^{2} \geqq r_{k}^{2} \geqq C_{k}^{2},
$$

where

$$
D_{k}^{2}=\frac{1}{x+\left(x^{2}+2(k+1) C_{k+1}^{1} / D_{k}^{1}\right)^{1 / 2}} \quad \text { and } \quad C_{k}^{2}=\frac{1}{x+\left(x^{2}+2(k+1) D_{k+1}^{1} / C_{k}^{1}\right)^{1 / 2}} .
$$


Then, by (29),

$$
\frac{C_{k+1}^{1}}{D_{k}^{1}} \geqq \frac{C_{k+1}^{0}}{D_{k}^{0}} \Rightarrow D_{k}^{1} \geqq D_{k}^{2} \quad \text { and } \quad \frac{D_{k+1}^{1}}{C_{k}^{1}} \leqq \frac{D_{k+1}^{0}}{C_{k}^{0}} \Rightarrow C_{k}^{2} \geqq C_{k}^{1} .
$$

Thus, for $m=1$ we have

$D_{k}^{0} \geqq D_{k}^{1} \geqq D_{k}^{2} \geqq r_{k} \geqq C_{k}^{2} \geqq C_{k}^{1}=C_{k}^{0} \quad$ and $\quad D_{k}^{0} \geqq D_{k}^{1} \geqq D_{k}^{2} \geqq r_{k}^{2} \geqq C_{k}^{2} \geqq C_{k}^{1}=C_{k}^{0}$ with strict inequality in $C_{k}^{2} \geqq C_{k}^{1}$ for $x>0$ because $D_{k}^{0}>D_{k}^{1}$ for $x>0$.

Continuing in this way, we compute inductively a sequence $D_{k}^{m}$ which is bounded and monotone decreasing while $C_{k}^{m}$ is bounded and monotone increasing with $r_{k}^{m}$ and $r_{k}$ between these bounds. Each sequence therefore has a limit $D_{k}$ and $C_{k}$ such that

$$
D_{k}=\frac{1}{x+\left(x^{2}+2(k+1) C_{k+1} / D_{k}\right)^{1 / 2}}, \quad C_{k}=\frac{1}{x+\left(x^{2}+2(k+1) D_{k+1} / C_{k}\right)^{1 / 2}} .
$$

Solving for each of these radicals and squaring gives

$$
D_{k}=\frac{1}{2 x+2(k+1) C_{k+1}}, \quad C_{k}=\frac{1}{2 x+2(k+1) D_{k+1}}
$$

and combining the relations in $(30)$ produces

$$
D_{k}=\frac{1}{2 x+\frac{2(k+1)}{2 x+2(k+2) D_{k+2}}}, \quad C_{k}=\frac{1}{2 x+\frac{2(k+1)}{2 x+2(k+2) C_{k+2}}} .
$$

Each of these lead to the continued fraction for $r_{k}$ which can be developed similarly by repeated application of (6). Therefore, $D_{k}=C_{k}=r_{k}$ and $r_{k}^{m}$ converges to $r_{k}$.

Acknowledgements. The author wishes to acknowledge the assistance of the referee for his part in clarifying the presentation and offering suggestions on several tedious details. The assistance of Mrs. Sharon L. Daniel is also appreciated for the coding of the numerical experiments for a CDC 6600 computer.

Appendix. Some Relations Involving $r_{n}, r_{n}^{\prime}$ and $r_{n}^{\prime \prime}$. We start with the selfadjoint differential equation

$$
\frac{d}{d t}\left(e^{t^{2}} y_{n}^{\prime}\right)=2 n e^{t^{2}} y_{n}, \quad n \geqq-1,
$$

and apply Green's theorem to the relation

$$
\int_{x}^{\infty}\left[y_{n-1} \frac{d}{d t}\left(e^{t^{2}} y_{n}^{\prime}\right)-y_{n} \frac{d}{d t}\left(e^{t^{2}} y_{n-1}^{\prime}\right)\right] d t=2 \int_{x}^{\infty} e^{t^{2}} y_{n}(t) y_{n-1}(t) d t
$$

to get

$$
y_{n-1} y_{n}^{\prime}-y_{n} y_{n-1}^{\prime}=-2 e^{-x^{2}} \int_{x}^{\infty} e^{t^{2}} y_{n}(t) y_{n-1}(t) d t, \quad n \geqq 1,
$$

or with (11),

$$
y_{n}(x) y_{n-2}(x)-y_{n-1}^{2}(x)=-2 e^{-x^{2}} \int_{x}^{\infty} e^{t^{2}} y_{n}(t) y_{n-1}(t) d t<0, \quad n \geqq 1 .
$$


Therefore,

$$
\begin{aligned}
& r_{n}^{\prime}(x)=\frac{y_{n} y_{n-2}}{y_{n-1}^{2}}-1=-\frac{2 e^{-x^{2}}}{y_{n-1}^{2}(x)} \int_{x}^{\infty} e^{t^{2}} y_{n}(t) y_{n-1}(t) d t<0, \\
& r_{n}^{\prime}(x)=\frac{r_{n}}{r_{n-1}}-1<0 \quad \text { and } \quad 0<\frac{r_{n}}{r_{n-1}}<1, \quad n \geqq 0 .
\end{aligned}
$$

The recursion relation (6), reciprocated and differentiated, provides the recursion relation for $r_{n}^{\prime}$,

$$
r_{n-1}^{\prime}=-2 r_{n-1}^{2}\left(1+n r_{n}^{\prime}\right)
$$

which shows that $r_{n}^{\prime}>-2 r_{n}^{2}$. On the other hand, a direct estimate of (32) using

$$
\begin{aligned}
\exp \left\{t^{2}-x^{2}\right\} & \geqq 1 \quad \text { for } t \geqq x \geqq 0, \\
& \geqq e^{-x^{2}} \quad \text { for } t \geqq x \text { and } x<0,
\end{aligned}
$$

and the differential form of (11) gives

$$
\begin{aligned}
-2 r_{n}^{2}<r_{n}^{\prime} & <-r_{n}^{2}, & & x \geqq 0, \\
& <-r_{n}^{2} \exp \left\{-x^{2}\right\}, & & x<0 .
\end{aligned}
$$

(34) in the form

$$
-r_{n-1}^{\prime} /\left(2 r_{n-1}^{2}\right)=1+n r_{n}^{\prime}>0
$$

also shows that

$$
r_{n}^{\prime}>-1 / n,
$$

which is better for large negative $x$ than (35). The recursion relation for $r_{n}^{\prime \prime}$ follows from (34) by differentiation,

$$
r_{n-1} r_{n-1}^{\prime \prime}+2 n r_{n-1}^{3} r_{n}^{\prime \prime}=2\left(r_{n-1}^{\prime}\right)^{2} .
$$

The positivity of $r_{n}^{\prime \prime}$ can be obtained from (32) as follows:

$$
\begin{aligned}
y_{n-1}^{3} r_{n}^{\prime \prime} & =y_{n-2}\left[y_{n} y_{n-2}-y_{n-1}^{2}\right]-y_{n}\left[y_{n-1} y_{n-3}-y_{n-2}^{2}\right] \\
& =-2 y_{n-2}(x) e^{-x^{2}} \int_{x}^{\infty} e^{t^{2}} y_{n}(t) y_{n-1}(t) d t+2 y_{n}(x) e^{-x^{2}} \int_{x}^{\infty} e^{t^{2}} y_{n-1}(t) y_{n-2}(t) d t \\
& =2 e^{-x^{2}} \int_{x}^{\infty} e^{t^{2}} y_{n-1}(t)\left[y_{n-2}(t) y_{n}(x)-y_{n-2}(x) y_{n}(t)\right] d t
\end{aligned}
$$

This gives, after factorization,

$$
y_{n-1}^{3} r_{n}^{\prime \prime}=2 e^{-x^{2}} \int_{x}^{\infty} e^{t^{2}} y_{n-1}(t) y_{n}(t) y_{n}(x)\left[\frac{1}{r_{n}(t) r_{n-1}(t)}-\frac{1}{r_{n}(x) r_{n-1}(x)}\right] d t>0 .
$$

This not only implies monotone increasing behavior of $r_{n}^{\prime}$ in $x$, but differentiation of (33) establishes monotone behavior in $n$ as well,

$$
r_{n-1} r_{n}^{\prime \prime}+r_{n-1}^{\prime} r_{n}^{\prime}=r_{n}^{\prime}-r_{n-1}^{\prime}>0
$$

or 


$$
0>r_{n}^{\prime}>r_{n-1}^{\prime} \text {. }
$$

Upper bounds on $r_{n}^{\prime \prime}$ can be obtained from (37) using $r_{n}^{\prime \prime}>0 . r_{n}^{\prime \prime}>0$ also establishes (40)

$$
r_{n}^{\prime} / r_{n}>r_{n-1}^{\prime} / r_{n-1}
$$

through differentiation of (33),

$$
r_{n}^{\prime \prime}=\frac{r_{n}}{r_{n-1}}\left(\frac{r_{n}^{\prime}}{r_{n}}-\frac{r_{n-1}^{\prime}}{r_{n-1}}\right)
$$

and with (33) again,

$$
1 / r_{n-1}-1 / r_{n}>1 / r_{n-2}-1 / r_{n-1} .
$$

That is, second differences $\delta^{2}\left(1 / r_{n-1}\right)$ are negative,

$$
\delta^{2}\left(1 / r_{n-1}\right)<0, \quad n=2,3, \cdots .
$$

(39) together with (33) also establishes the monotone decreasing behavior of the differences $r_{n-1}-r_{n}$,

$$
0<r_{n-1}-r_{n}<\left(r_{n-2}-r_{n-1}\right) r_{n-1} / r_{n-2}<\left(r_{n-2}-r_{n-1}\right)
$$

and hence

$$
\delta^{2}\left(r_{n-1}\right)>0, \quad n=2,3, \cdots .
$$

The expression in (31) is the numerator of

$$
\frac{d^{2}}{d x^{2}} \ln y_{n}(x)=\frac{y_{n} y_{n-2}-y_{n-1}^{2}}{y_{n}^{2}}<0, \quad n \geqq 1 \text {. }
$$

For $n=0$ this works out to be

$$
\frac{d^{2}}{d x^{2}} \ln y_{0}(x)=-\frac{2 y_{-1}(x) y_{1}(x)}{y_{0}^{2}(x)}<0 .
$$

Thus we have also established that $w=\ln i^{n} \operatorname{erfc}(x)$ is concave down for all $x$ and all $n \geqq 0$.

A Sharp Upper Bound on a Gamma Ratio. We start with the asymptotic expansion [1, p. 257]

$$
\ln \Gamma(z)=\left(z-\frac{1}{2}\right) \ln z-z+\frac{1}{2} \ln 2 \pi+\frac{1}{12 z}-\frac{1}{360 z^{3}}+R
$$

for $z>0$ and estimate $R$ by the next term $|R| \leqq 1 /\left(1260 z^{5}\right)$. The application of the final results dictated this accuracy. This expression can be applied for $z=x+1$ and $z=x+\frac{1}{2}$ to yield

$$
\begin{aligned}
\ln \frac{\Gamma(x+1)}{\Gamma\left(x+\frac{1}{2}\right)}= & \frac{1}{2} \ln x+\left(x+\frac{1}{2}\right) \ln \left(1+\frac{1}{x}\right)-x \ln \left(1+\frac{1}{2 x}\right)-\frac{1}{2} \\
& +\frac{1}{12 x}\left[\left(1+\frac{1}{x}\right)^{-1}-\left(1+\frac{1}{2 x}\right)^{-1}\right] \\
& -\frac{1}{360 x^{3}}\left[\left(1+\frac{1}{x}\right)^{-3}-\left(1+\frac{1}{2 x}\right)^{-3}\right]+R_{1}-R_{2}
\end{aligned}
$$


where

$$
\left|R_{1}\right| \leqq 1 /\left(1260 x^{5}\right), \quad\left|R_{2}\right| \leqq 1 /\left(1260 x^{5}\right) .
$$

Now, the following alternating series for $x \geqq 2$ can be used for terms up to and including $x^{-4}$ in (44),

$$
\begin{array}{rlrl}
\ln \left(1+\frac{1}{x}\right) & =\frac{1}{x}-\frac{1}{2 x^{2}}+\frac{1}{3 x^{3}}+R_{4}\left(\frac{1}{x}\right), & & \left|R_{4}\left(\frac{1}{x}\right)\right| \leqq \frac{1}{4 x^{4}}, \\
=\frac{1}{x}-\frac{1}{2 x^{2}}+\frac{1}{3 x^{3}}-\frac{1}{4 x^{4}}+R_{5}\left(\frac{1}{x}\right), & & \left|R_{5}\left(\frac{1}{x}\right)\right| \leqq \frac{1}{5 x^{5}}, \\
\left(1+\frac{1}{x}\right)^{-1}=1-\frac{1}{x}+\frac{1}{x^{2}}+\bar{R}_{3}\left(\frac{1}{x}\right) & \left|\bar{R}_{3}\left(\frac{1}{x}\right)\right| \leqq \frac{1}{x^{3}}, \\
\left(1+\frac{1}{x}\right)^{-3}=1+\hat{R}_{1}\left(\frac{1}{x}\right), & \left|\hat{R}_{1}\left(\frac{1}{x}\right)\right| \leqq \frac{3}{x}
\end{array}
$$

Then

$$
\ln \frac{\Gamma^{2}(x+1)}{\Gamma^{2}\left(x+\frac{1}{2}\right)}=\ln x+\frac{1}{4 x}-\frac{1}{96 x^{3}}+E
$$

where

$$
\begin{aligned}
E= & R_{4}\left(\frac{1}{x}\right)+2 x R_{5}\left(\frac{1}{x}\right)-2 x R_{5}\left(\frac{1}{2 x}\right)+\frac{1}{6 x}\left[\bar{R}_{3}\left(\frac{1}{x}\right)-\bar{R}_{3}\left(\frac{1}{2 x}\right)\right] \\
& -\frac{1}{180 x^{3}}\left[\hat{R}_{1}\left(\frac{1}{x}\right)-\hat{R}_{1}\left(\frac{1}{2 x}\right)\right]+2 R_{1}-2 R_{2}
\end{aligned}
$$

and

$$
|E|<1 / x^{4}, \quad x \geqq 2 .
$$

For consistency, terms of degree three or less are carried accurately in estimating the exponential

$$
\begin{aligned}
\frac{\Gamma^{2}(x+1)}{\Gamma^{2}\left(x+\frac{1}{2}\right)} & =x e^{\alpha}=x\left(1+\alpha+\frac{\alpha^{2}}{2}+\frac{\alpha^{3}}{6}+\sum_{i=4}^{\infty} \frac{\alpha^{i}}{i !}\right) \\
& <x\left(1+\alpha+\frac{\alpha^{2}}{2}+\frac{\alpha^{3}}{6}+\frac{1}{4 !} \sum_{i=4}^{\infty} \alpha^{i}\right) \\
& <x\left(1+\alpha+\frac{\alpha^{2}}{2}+\frac{\alpha^{3}}{6}+\frac{\alpha^{4}}{4 !(1-\alpha)}\right)
\end{aligned}
$$

where

$$
\alpha=1 /(4 x)-1 /\left(96 x^{3}\right)+E, \quad 0<\alpha<3 / 16, \quad x \geqq 2 .
$$

Now we expand the powers of $\alpha$ and bound terms of higher order,

$$
x^{-i} \leqq x^{-4} / 2^{i-4}, \quad j \geqq 5, x \geqq 2,
$$

to obtain 


$$
\frac{\Gamma^{2}(x+1)}{\Gamma^{2}\left(x+\frac{1}{2}\right)}<x\left(1+\frac{1}{4 x}+\frac{1}{32 x^{2}}-\frac{1}{128 x^{3}}+\frac{6}{5 x^{4}}\right), \quad x \geqq 2 .
$$

This expression is asymptotically correct in all terms except the last.

Applied Mathematics Division

Sandia Laboratories

Albuquerque, New Mexico 87115

1. M. Abramowitz \& I. A. Stegun (Editors), Handbook of Mathematical Functions, With Formulas, Graphs and Mathematical Tables, Nat. Bur. Standards Appl. Math. Series, 55, Superintendent of Documents, U.S. Government Printing Office, Washington, D.C., 1964. MR 29 \#4914.

2. D. F. Barrow \& A. C. COHEN, JR., "On some functions involving Mill's ratio," Ann. Math. Statist., v. 25, 1954, pp. 405-408. MR 15, 807.

3 Z. W. BirnbauM, "An inequality for Mill's ratio," Ann. Math. Statist., v. 13, 1942, pp. 245-246. MR 4, 19.

4. A. V. BoYD, "Inequalities for Mills' ratio," Rep. Statist. Appl. Res. Un. Japan. Sci. Engrs., v. 6, 1959, pp. 44-46. MR 22 \#9625.

5. W. GAUTSCHI, "Computational aspects of three-term recurrence relations," SIAM Rev., v. 9, 1967, pp. 24-82. MR 35 \#3927.

6. W. GAUTSCHI, "Recursive computation of the repeated integrals of the error function," Math. Comp., v. 15, 1961, pp. 227-232. MR 24 \#B2113.

7. R. D. GoRDON, "Values of Mills' ratio of area to bounding ordinate and of the normal probability integral for large values of the argument," Ann. Math. Statist., v. 12, 1941, pp. 364-366. MR 3, 171.

8. Y. KomATu, "Elementary inequalities for Mills' ratio," Rep. Statist. Appl. Res. Un. Japan. Sci. Engrs., v. 4, 19:55, pp. 33-34.

9. K. B. OldhaM, "Approximations for the $x$ exp $x^{2}$ erfc $x$ function," Math. Comp., v. 22,1968 , p. 454.

10. H. O. Pollak, "A remark on "Elementary inequalities for Mills' ratio," by Y. Komatu," Rep. Statist. Appl. Res. Un. Japan. Sci. Engrs., 4, 1956, p. 40. MR 18, 722.

11. W. D. RaY \& A. E. N. T. Pitman, "Chebyshev polynomial and other new approximations to Mills' ratio," Ann. Math. Statist., v. 34, 1963, pp. 892-902. MR 27 \#3070.

12. H. RUBEN, "A convergent asymptotic expansion for Mills' ratio and the normal probability integral in terms of rational functions," Math. Ann., v. 151, 1963, pp. 355-364. MR 27 \#5308.

13. H. Ruben, "A new asymptotic expansion for the normal probability integral and Mills' ratio," J. Roy. Statist. Soc. Ser. B, v. 24, 1962, pp. 177-179. MR 25 \#2662.

14. H. RUBEN, "Irrational fraction approximations to Mills' ratio," Biometrika, v. 51, 1964, pp. 339-345. MR 30 \#3519.

15. M. R. SAMPFORD, "Some inequalities on Mills' ratio and related functions," Ann. Math. Statist., v. 24, 1953, pp. 130-132. MR 14, 995.

16. L. R. SHENTON, "Inequalities for the normal integral including a new continued fraction," Biometrika, v. 41, 1954, pp. 177-189. MR 15, 884.

17. R. F. TATE, "On a double inequality of the normal distribution," Ann. Math. Statist., v. 24,1953 , pp. 132-134. MR 14, 995.

18. V. R. R. UpPULURI, "A stronger version of Gautschi's inequality satisfied by the gamma function," Skand. Aktuarietidskr. v. 1-2, 1964, pp. 51-52. MR 31 \#4934. 